Protestantismo em Revista é licenciada sob uma Licença Creative Commons.

http://dx.doi.org/10.22351/nepp.v43i01.2997

\title{
Ética e sentido da vida: contribuições para a teologia no espaço público a partir de Clodovis Boff
}

\author{
Ethics and the meaning of life: contributions for theology in the public space from \\ Clodovis Boff
}

Jefferson Zeferino*

\begin{abstract}
Resumo
Em nossa análise buscamos uma aproximação crítica da elaboração de Clodovis Boff sobre o sentido da vida, relacionando-a com a assim chamada Teologia Pública. Assim, por meio da relação de fundo sobre ser e fazer - em um contexto de crises, com destaque para a crise existencial e, em consequência, crise ética e de valores - pensa-se uma ética pertinente ao contexto brasileiro, bem como a incidência pública de uma determinada práxis e espiritualidade cristãs.
\end{abstract}

Palavras-chave

Clodovis Boff. Teologia Pública. Sentido da Vida. Espiritualidade. Ética.

\begin{abstract}
The current work performs a critical approach to Clodovis Boff's theoretical elaboration regarding to the meaning of life relating it to the so called Public Theology. Thus, through the background relation of being and doing - in a context of crisis, highlighting the existential, ethical and values crisis - the work concentrates on the possibility of a relevant ethics to the Brazilian context so as it analyses the public incidence of Christina praxis and spirituality.
\end{abstract}

\section{Keywords}

Clodovis Boff. Public Theology. Meaning of Life. Spirituality. Ethics

\section{Considerações iniciais}

A questão de fundo aqui proposta é a relação entre ser e agir. Isto é, entendemos que o ser humano tal como ele é determina aquilo que faz. Por isso, pensar ética e sentido

[Texto recebido em março de 2016 e aceito em junho de 2017, com base na avaliação cega por pares realizada por pareceristas ad hoc]

* Bacharel em Teologia (FLT). Mestre e Doutorando em Teologia (PUCPR). Bolsista CAPES. Membro do grupo de pesquisa Teopatodiceia: Espiritualidade, Cultura, Práxis (PUCPR). Membro do Movimento Ecumênico de Curitiba (MOVEC). Membro da Igreja Evangélica de Confissão Luterana no Brasil (IECLB). E-mail: jefferson.zeferino@hotmail.com 
da vida, trata-se de pensar a ação por meio de sua fundamentação ontológica. O caminho de nossa elaboração teórica estrutura-se em três etapas: 1 . O problema da crise de sentido da vida; 2. O conceito de sentido em Clodovis Boff; 3. Impulsos do pensamento de C. Boff para a teologia na esfera pública.

Nossa pesquisa coloca em desenvolvimento algumas intuições não pretendendo esgotar o tema. Este texto, portanto, reflete a relação entre ética e sentido da vida a partir do pensamento de Clodovis Boff em breve diálogo com a assim chamada teologia pública. ${ }^{1}$

\section{A crise de sentido da vida e sua relação com a ética}

Ética e sentido da vida estão intimamente ligadas na medida em que quem age e sente é o mesmo ser. Como entende C. Boff no contexto da espiritualidade cristã:

Ora, a unidade de conhecimento e de amor é perfeitamente possível porque fundada em um sujeito único, que é o homem. De fato, não é propriamente a inteligência que entende e o coração que ama, mas é o próprio homem por inteiro que entende e ama. ${ }^{2}$

Dito de outra forma, é o próprio homem que é e age. Há uma óbvia relação entre ser e fazer. Por isso, parece que o drama da falta de um sentido último que aprofunde a experiência humana em suas relações faz com que se corra o risco de uma intensificação do humano enquanto homo incurvatus in se e insensível à realidade de sofrimento do outro. Leonardo Boff, em convergência com Clodovis Boff no que tange à identificação de uma crise de sentido no homem contemporâneo, aponta que:

O drama do homem atual é ter perdido a capacidade de viver um sentimento de pertença, coisa que as religiões sempre garantiam. O que se opõe à religião não é o ateísmo ou a negação da divindade. O que se opõe é a incapacidade de ligar-se e religar-se com todas as coisas. Hoje as pessoas

1 Este texto se coloca historicamente no momento da recente aposentadoria de Clodovis Boff de sua atuação como Professor Titular do Programa de Pós-Graduação em Teologia da Pontifícia Universidade Católica do Paraná, PUCPR. Além de uma história consolidada como Professor na Pontifícia Universidade Católica do Rio de Janeiro e na Pontificia Facoltà Teologica Marianum de Roma, bem como em outras importantes Instituições de Ensino Superior. Cabe ressaltar também sua marcante contribuição com a pastoral junto a comunidades do Acre e do Rio de Janeiro. Boff foi orientador do autor do presente artigo em seu mestrado e em parte de sua pesquisa de doutoramento. Neste sentido, o trabalho aqui apresentado também cumpre a função de uma singela homenagem a um dos mais destacados articuladores da Teologia da Libertação.

2 BOFF, C. Teologia e espiritualidade: por uma teologia que ilumine a mente e inflame o coração. Rev. Pistis Prax. Teol. Pastor., Curitiba, v. 7, n. 1, jan./abr. 2015. p. 121. 
estão desenraizadas, desconectadas da Terra e da anima que é a expressão da sensibilidade e da espiritualidade. ${ }^{3}$

Desta forma, esta incapacidade de desencurvar-se de si em favor do outro é vista aqui como uma crise profunda da existência. Trata-se de uma crise de sentido da vida.

As religiões, nesta dimensão, podem contribuir tanto na construção de sentido quanto na publicidade política, efetiva e transformadora de suas propostas de espiritualidade. Nesta direção, já Karl Barth ${ }^{4}$ apontava para a impossibilidade de uma existência apolítica das comunidades eclesiais. Uma vez parte da polis, isto é, enquanto constituinte da comunidade civil, a incidência pública da Igreja se torna factual, o ponto a ser investigado é como sua presença afeta a sociedade.

Compreende Rudolf von Sinner que “a dimensão pública da religião está voltando com força ao discurso acadêmico". ${ }^{5}$ Além disso, é necessário observar o grande quadro de crescente pluralismo religioso no mundo ocidental. “O pluralismo, o respeito por outras opiniões e a negociação são elementos essenciais para uma sociedade democrática e seu discurso público". ${ }^{6}$ Em virtude disso, para Sinner:

Uma teologia pública que pretenda refletir sobre a contribuição que as igrejas podem dar no espaço público, visando ao bem ou bem-estar comum, deve tanto incentivar essa contribuição entre as pessoas que tendem a ver o mundo como mal e a se enclausurar em suas igrejas como a comunidade dos que esperam a segunda vinda de Cristo quanto restringila entre as que desejam impor sua crença, seus valores, interesses corporativos e poder ao todo da sociedade. Ambos os fenômenos estão presentes globalmente, também no Brasil. Uma teologia pública visa dar orientação às igrejas quanto à sua atuação além de sua membresia, em diálogo constante com a sociedade (civil) e a universidade, a economia, a mídia e outros "públicos".7

Em nossa análise damos um passo atrás, e pretendemos pensar o caráter existencial da fé no horizonte do sentido da vida. Ora, o ser que existe em comunidade e age politicamente o faz também em virtude de suas crenças e percepções de sentido que entende como verdadeiras. Em uma leitura teológica cristã, fazemos uma aproximação do conceito de sentido a partir da obra de Clodovis Boff intitulada O livro do sentido: crise $e$ busca de sentido hoje (parte crítico-analítica), mais especificamente nas páginas em que o

3 BOFF, L. A urgência de uma ecologia integral. Disponível em: <https://leonardoboff.wordpress.com/2015/11/10/a-urgencia-de-uma-ecologia-integral>. Acesso em: 21 jan. 2016.

4 BARTH, K. Comunidade cristã e comunidade civil. In: BARTH, K. Dádiva e louvor: ensaios teológicos de Karl Barth. São Leopoldo: Sinodal/EST, 2006. p. 291-292.

5 SINNER, R. Teologia pública: um olhar global. In: ZWETSCH, R.; CAVALCANTE, R.; SINNER, R. (Orgs.). Teologia Pública: em debate. São Leopoldo: Sinodal/EST, 2011. p. 11.

6 SINNER, 2011, p. 12.

7 SINNER, 2011, p. 12. 
autor desenvolve o significado do termo sentido. Desta forma, é por meio da análise do sentido de sentido que se pretende encontrar recursos para se pensar a posteriori a dimensão comunitária e pública da fé.

\section{O sentido do termo sentido em Clodovis Boff}

Para Clodovis Boff, a pergunta pelo sentido da vida é uma questão existencial. ${ }^{8} \mathrm{E}$ no primeiro capítulo de sua obra ele se ocupa com "uma reflexão semântico-filosófica, necessária para a clareza do debate subsequente". Pois, para ele, "por falta de precisar o que está em jogo na palavra 'sentido', o debate vê-se privado de foco, levando a especulações fora de propósito" o que impede "o encaminhamento correto das saídas possíveis". 9 O autor propõe uma análise pormenorizada na busca do sentido do termo sentido. ${ }^{10}$

Clodovis inicia sua abordagem tratando do tema do sentido enquanto finalidade. Pois, para ele, ao se falar de sentido da vida se fala de seu fim enquanto finalidade. ${ }^{11}$ Ao falar sentido ou fim da vida, também se tem em mente o pensamento de um fim último, ou um bem supremo. Ora, o sentido está em sua finalidade, em seu fim, "aquilo por causa do quê". ${ }^{12}$ Daí também a relação entre o bem, o fim e o ser. Esta teleologia possui inúmeras implicações éticas e metafísicas. Tal pensamento, em Aristóteles, culmina na teologia, isto é, na ideia de Deus como fim supremo, o qual serve de modelo para o homem inteligente. A ideia de Aristóteles, portanto, é a de que o mundo é ordenado, que o fim das coisas está relacionado ao bem enquanto finalidade. Além da ideia de Deus como instância última, o que é essencial para Clodovis, uma vez que, para ele, tirando Deus da equação lega-se ao mundo dimensões apenas penúltimas, abrindo-se as perspectivas niilistas. Observa ainda o teólogo servita que também as religiões se ocuparam com o problema da finalidade das coisas, ou para que fim foram as coisas criadas. Este "para quê" das religiões em última análise é a pergunta pelo sentido das coisas, que é a pergunta pela finalidade da vida. ${ }^{13}$

Num segundo momento, o autor trata o termo sentido enquanto valor. Para C. Boff, os termos finalidade e sentido também podem ser entendidos desta forma. Pois, por trás do problema da crise de valores - o que está relacionado com o problema da ética encontra-se o problema do sentido/valor a vida. Isto ocorre porque o próprio sentido da moral precisa se ancorar em algo maior para não ser um fim em si mesmo. Enfim, para o autor, o valor também está relacionado com o conceito de bem. Daí que se pode tratar das

8 BOFF, C. O livro do sentido: crise e busca de sentido hoje (parte crítico-analítica). São Paulo: Paulus, 2014. p. 7.

9 BOFF, 2014, p. 8-9.

10 BOFF, 2014, p. 11-12.

11 BOFF, 2014, p. 13.

12 BOFF, 2014, p. 14.

13 BOFF, 2014, p. 15-17. 
equivalências entre valor, fim e bem. Assim, dizer que a vida tem valor, é dizer que ela é boa e que tem sentido, sendo boa por ter uma finalidade, um sentido. ${ }^{14}$

Assim, para o autor, se a vida tem valor, o bem se torna qualidade transversal a todos os seres, sendo o valor um bem ontológico que não pode ser delegado a alguém, pois este já o é em si. Deus, que é ontologicamente o ser mais denso, não possui sentido, mas é, ele próprio, "valor valorante" e o "sentido dos sentidos". Também um grão de areia possui valor, mas por sua pouca densidade ontológica possui menos valor. Enquanto que o nada caracteriza o não ser e o mal o "antisser" - aquele que nega o ser. Desta forma, o empobrecimento do conceito de ser, ou sua desvalorização tem a ver com o empobrecimento de sua fundamentação. Em virtude disso, compreende o autor que a sociedade consumista se encontra em profunda crise ontológica, pois fundamenta-se no materialismo. ${ }^{15}$

Em seguida, o autor trabalha a articulação entre sentido e valor, termos que, para ele, são sinônimos. O termo valor, por sua vez, também pode ser compreendido em perspectiva ética. Nesta direção, pode existir a ideia de um valor último ou o valor que dá valor. ${ }^{16}$

Outro aspecto abordado por Clodovis é sentido enquanto direção. Segundo ele, é intrínseco ao conceito de sentido "estar voltado para", isto é, ter um sentido é ter uma direção para alguma outra realidade. Quanto ao sentido da vida, se reforça a ideia de ela ter seu sentido para fora de si mesma. O sentido ético e espiritual da vida é dado através do reconhecimento de sua finalidade, seu fim, que novamente dá direção a vida. Por isso, sentido enquanto direção e finalidade dependem do "valor valorante" ${ }^{17}$

O desenvolvimento teórico de Clodovis introduz a máxima de que o fim é sentido enquanto causa, ou seja, ele é sentido, pois confere sentido. O fim determina a direção. E por mais que semanticamente sentido tem a ver antes com direção do que com fim, existencialmente pode se dizer que sentido enquanto fim precede sua noção enquanto direção, uma vez que um causa o outro. ${ }^{18}$

Assim, ao se falar de direção e fim, também se pode falar de caminho e destino. Na fé cristã, este caminho ocorre em Cristo na direção do Pai, sendo que é o destino que revela o caminho. Daí que o desorientado ou desnorteado é aquele desprovido de um fim. ${ }^{19}$ Para Clodovis, o fim enquanto direcionador da existência dá sentido as questões éticas e espirituais. ${ }^{20}$

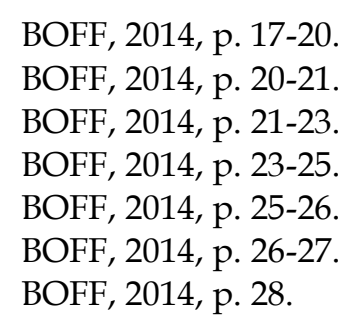


Desta sua análise "semântico-existencial" compreende o autor:

\begin{abstract}
"Sentido" é fundamentalmente "fim". "Fim" é sempre um "valor" ou um "bem" que o ser humano e as coisas em geral buscam. Portanto, falar em "sentido da vida" é falar na "finalidade da vida" ou no "valor da vida", real ou potencial que seja. Ademais, o fim é uma potência extremamente ativa. É uma causa: a "causa final". Tal causa tem o primado sobre todas as outras. É ela que confere à vida: direção ética e espiritual, razão de ser ou inteligibilidade, motivação ou estímulo para viver, esperança de chegar à própria realização, centralidade e harmonia de viver e, ainda, alegria de estar no caminho certo e encantamento ou graça em tudo o que se vive e se faz. ${ }^{21}$
\end{abstract}

Em outra parte de sua obra Clodovis Boff acessa a problemática do sentido por outros vieses. Para ele, a questão do sentido enquanto função pode ocorrer em certos momentos dado ao sentido/função de determinadas coisas, como o carro que possui seu sentido no serviço de transportar pessoas. Ou seja, função pode ser vista mais como serviço, porém, tratá-la como metáfora para sentido tem suas limitações visíveis devido a sua veiculação com o mecanicismo e o funcionalismo. ${ }^{22}$

Acerca do conceito de sentido enquanto verdade, o autor reflete que verdade é sinônimo de fim, enquanto causalidade e conteúdo. Assim, a pergunta pela verdade também é a pergunta pelo sentido da vida. Desta forma, apenas a verdade verdadeira é capaz de preencher a vida verdadeiramente e dar-lhe sentido último. ${ }^{23}$

C. Boff também elabora que conceitualmente é possível traçar uma relação entre sentido e essência, partindo da ideia da essência do ser, porém este ser/essência em si mesmo é precário, pois o sentido último da vida precisa estar fora do ser humano. ${ }^{24}$ Isto é, para que exista um sentido para fora de si é necessário que o sentido esteja fora do ser. Há sim o sentido de si e para si, a verdade do ser enquanto construção de si. Entretanto, a pergunta por um sentido para além de si mesmo leva a questão de Deus.

Por fim, o autor fala sobre a invisibilidade e perceptibilidade do sentido. O sentido não é visível, mas está no interior das coisas. A falta de Sentido maiúsculo consiste no empobrecimento da sensibilidade do olhar humano para fora de si. Segundo Clodovis, é necessário ver que na fé cristã o Sentido se fez carne, fazendo-se visível, sendo caminho, direção, fim/ finalidade. ${ }^{25}$

\footnotetext{
BOFF, 2014, p. 35.

BOFF, 2014, p. 55-57.

BOFF, 2014, p. 57-58.

BOFF, 2014, p. 58-59.

BOFF, 2014, p. 59-62.
} 
No capítulo conclusivo de seu livro, Clodovis trabalha propostas atuais de sentido, entre elas pontua a questão da ética. Para ele, a ética enquanto vetor de sentido consiste nas seguintes perspectivas: ${ }^{26}$

1. Ideais humanitários têm a capacidade de prover sentido enquanto finalidade da vida. Que pode ser chamado de amor ao próximo, uma vez que vidas voltadas à paz, à luta contra a pobreza e contra as injustiças são vistas como vidas carregadas de sentido. Porém, apesar de ter a vida ocupada de sentido tanto os que lutam pelas causas humanas quanto os destinatários desta luta possuem uma vontade interior ainda maior, o ser humano humanizado, em condições e com recursos para se desenvolver humanamente não encontra a plenitude da vida na ética, pois a vida é mais que social, consiste também em sua esfera espiritual, na qual o homem se abre ao infinito. Não somente da ética, mas da espiritualidade veio a força de muitas pessoas que lutaram pelos seres humanos no século XX, sendo muitos deles martirizados. ${ }^{27}$

2. Boff ressalta que a ética laica de ateus e agnósticos honestos existe e merece crédito sob os exemplos de personalidades como Freud, Bobbio e Niemeyer. Sempre há aqueles que se comovem com os injustiçados e se movem eticamente em sua direção. Neste pensamento que subtrai Deus da lógica da vida, é possível que a vida tenha valor, na medida em que se vive moralmente de forma digna. Conviver com o vazio da existência é parte da vida do herói estoico. Assim, o homem moderno maduro é aquele que vive dignamente o absurdo do sem sentido. Para Clodovis, esta ética somente imanentista pode enfrentar o absurdo, mas jamais superá-lo, pois nenhuma ética supera a radicalidade da morte se desassociada da espiritualidade. ${ }^{28}$

Por fim, Clodovis enfatiza a importância do agir ético baseado na ontologia. Para ele, todo agir moral se fundamenta em um absoluto/bem. Aqui se percebe que o ser está antes mesmo do agir. E ao se falar de um bem absoluto na fundamentação da ética se fala de Deus, o qual é capaz de nutrir espiritualmente o agir ético do ser humano. Para o autor, este agir moral, sem suporte divino, cansa e causa incoerências. A ética ateia corre o risco da incoerência e da arrogância, pois a humildade consiste em uma virtude religiosa, pois as virtudes do incrédulo são limitadas ao ser em si. ${ }^{29}$

Ao concluir suas considerações acerca da ética enquanto vetor de sentido, ele observa que:

Ao termo do exame das propostas éticas, oferecidas hoje à questão do sentido, fica mais clara a tese fundamental, subtendida a toda a nossa reflexão: sem o Transcendente, a ética rateia e o sentido não se ultima. Sem

\footnotetext{
BOFF, 2014, p. 539-540.

BOFF, 2014, p. 540-543.

BOFF, 2014, p. 543-548.

BOFF, 2014, p. 548-541.
} 
a bússola de Deus, o homem não só perde com facilidade o norte moral, mas fica à deriva no oceano da existência. ${ }^{30}$

Boff não nega que exista sentido sem Deus, mas entendendo Deus como o sentido último da existência, porém, ao negligenciá-lo enquanto realidade, o sentido deve ser confrontado com o niilismo e com a limitação da vida em si mesma. Desta forma, o autor intenta centrar o conceito de sentido em sua esfera existencial e espiritual. Deus é o fundamento do sentido, sendo ele mesmo sentido que confere sentido a todas as coisas. Desta maneira, pode-se compreender Deus também como o fundamento da ética, pois sendo o fundamento do ser também se faz o fundamento do agir do ser.

Da análise do pensamento do teólogo servita compreendemos que a ética é dimensionada pelo sentido da vida. Esta ética, porém, enquanto pensada a partir da realidade do Deus cristão, está no ambiente da Criação, e percebe a realidade societária da existência sob a luz de Jesus Cristo. Com isso, a ética plasmada pela espiritualidade cristã não deve ser vista como restrita ao espaço eclesial, mas possui incidência na sociedade. Desta forma, a assim chamada esfera pública é espaço privilegiado da atuação cristã.

\section{Sentido da vida e teologia no espaço público}

$\mathrm{O}$ aspecto existencial (sentido da vida) influencia a dimensão social (ética). Desta forma, um sentido de vida como aquele das comunidades eclesiais terá, querendo ou não, incidências no espaço público. A questão é analisar se a incidência pública desta ética dimensionada pelo sentido da vida segue, efetivamente, a pista da ética de Jesus ou não. Uma forma de pensar esta incidência pública da fé cristã é o que tem sido chamado de teologia pública. Desta forma, o pensamento clodovisiano de sentido da vida pode ser uma interlocução apropriada à teologia no espaço público na medida em que aponta para uma antropologia excêntrica (kenosis).

Antes de pensarmos as contribuições do pensamento de C. Boff para a ética na esfera pública, cabe introduzir brevemente o que se entende por teologia pública. Utilizamo-nos neste espaço da obra de Rudolf von Sinner, um dos principais teóricos da teologia pública no Brasil. Apesar de suíço, von Sinner vive e leciona no Brasil já há mais de uma década, tendo recentemente desenvolvido uma importante análise da democracia no Brasil e do papel das igrejas neste contexto, ${ }^{31}$ propondo a assim chamada teologia da cidadania como uma teologia pública para a realidade brasileira.

De acordo com von Sinner, "a fé cristã é eminentemente pública - e, portanto, também a teologia que sobre ela reflete". Para ele, "as igrejas e seus teólogos e, mais recentemente, também suas teólogas sempre têm se pronunciado a respeito de assuntos de

30 BOFF, 2014, p. 551.

31 SINNER, R. The Churches and democracy in Brazil: towards a public theology focused on citizenship. Eugene: Wipf \& Stock, 2012. 
interesse público [...]. Se o conteúdo é, portanto, milenar, o conceito de uma 'teologia pública' é relativamente recente" ${ }^{32}$

Sobre a história do termo teologia pública, Sinner aponta que:

Em 1974, o teólogo norte-americano Marvin E. Marty cunhou o termo, designando com ele contribuições religiosas no espaço público como feitas por pessoas como Jonathan Edwards, Abraham Lincoln e Reinhold Niebuhr nos Estados Unidos dos séculos XVIII a XX. A questão do papel da religião, especificamente da fé cristã, no contexto estadunidense já data de antes disso, quando, em 1967, Robert N. Bellah falou de uma "religião civil", referências religiosas usadas por políticos para dar coesão à sociedade, assim constituindo uma religião oriunda do cristianismo, mas não diretamente ligada às igrejas. Algo semelhante formou-se no Brasil do regime militar, quando a "educação moral e cívica" introduziu um tipo de religião civil brasileira (Thales de Azevedo). Contudo, diferente da religião civil, a teologia pública está claramente enraizada na fé e teologia cristãs, querendo levar a sério sua tarefa no espaço público. ${ }^{33}$

David Tracy, um dos principais articuladores da teologia pública no contexto americano, por sua vez, "falou de três diferentes públicos da teologia: a sociedade, a academia e a igreja, e foram sendo acrescentados outros públicos por outros autores, como a economia e a mídia".34

Para Sinner, "embora o termo seja pouco usado na América Latina atualmente, ${ }^{35} \mathrm{o}$ conteúdo não é novidade". ${ }^{36}$ A teologia pública "retoma muitas intuições da Teologia da

32 SINNER, R. Teologia pública. In: SINNER, R. Confiança e convivência: reflexões éticas e ecumênicas. São Leopoldo: Sinodal, 2007. p. 43.

33 SINNER, 2007, p. 43.

34 SINNER, 2007, p. 43.

35 Vale destacar que o texto base aqui utilizado é de 2007, de lá para cá avanços significativos foram feitos no pensamento da teologia pública no Brasil, teses foram defendidas sobre o tema além da série Teologia Pública da Editora Sinodal juntamente com as Faculdades EST vem somando qualitativamente para o desenvolvimento do tema. Sobre isto ver: BARRETO, J. A presença pública da Igreja na cidade: análise das práticas pastorais da Igreja Metodista em Belo Horizonte (1982 a 2006) frente aos desafios das transformações socioculturais. Tese (Doutorado). Universidade Metodista de São Paulo, Faculdade de Humanidades e Direito, São Bernardo do Campo, 2013. BUTTELLI, F. E a luta continua: propostas para uma teologia pública libertadora para o desenvolvimento construída em diálogo com a reflexão teológica sul-africana. Tese (Doutorado). Escola Superior de Teologia, Programa de Pós-Graduação, São Leopoldo, 2013. BUTTELLI, F.; LE BRUYNS, C.; SINNER, R. (Orgs.). Teologia pública no Brasil e na África do Sul: cidadania, interculturalidade e HIV/AIDS. São Leopoldo: Sinodal/Faculdades EST, 2014. CAVALCANTE, R.; SINNER, R. A cidade e o gueto: introdução a uma teologia pública protestante e o desafio do neofundamentalismo evangélico no Brasil. São Paulo: Fonte Editorial, 2010. CAVALCANTE, R.; SINNER, R. (Orgs.). Teologia pública: em debate. São Leopoldo: Sinodal/Faculdades EST, 2011. GMAINER-PRANZL, F.; JACOBSEN, E (Orgs.). Teologia pública: deslocamentos da teologia contemporânea. São Leopoldo: Sinodal/Faculdades EST, 2015. JACOBSEN, E. Teologia e teoria política: aproximações críticas entre correntes da teologia contemporânea e o pensamento político de Jürgen Habermas. Tese (Doutorado). Faculdades EST, Programa de Pós-Graduação, São Leopoldo, 2015. JACOBSEN, E.; SINNER, R.; ZWETSCH, R.; KLEIN, R. (Orgs.). Teologia pública: desafios sociais e culturais. São Leopoldo: Sinodal/Faculdades EST, 2012. JACOBSEN, E.; SINNER, R.; ZWETSCH, R.; STRECK, V. (Orgs.). Teologia pública: desafios éticos e teológicos. São Leopoldo: Sinodal/Faculdades EST, 
Libertação latino-americana, que preparou a base para uma forma de pensamento que sustenta e torna plausível a importância fundamental do aspecto contextual da teologia, especialmente em vista de suas dimensões econômicas, políticas e sociais" ${ }^{37}$ A teologia entendida como pública "parte de um contexto específico e interage com ele", não estando restrita a um determinado espaço. 38

A teologia pública, portanto, é aquela que se coloca na interface, principalmente, entre teologia e academia, teologia e igreja, teologia e sociedade, podendo relacionar-se também com outros públicos. A análise de Clodovis Boff, como se trata de uma pesquisa de ordem fundamental, isto é, concentra-se no aspecto antropológico serve de base para se pensar o humano dentro da teologia em suas variadas interfaces. ${ }^{39}$

Desta forma, da abordagem de Clodovis é possível compreender o seguinte caminho no que tange o debate do envolvimento do cristão na esfera pública:

\section{Jesus Cristo $\rightarrow$ Sentido da vida $\rightarrow$ Ética $\rightarrow$ Política $\rightarrow$ Espaço Público}

No pensamento do teólogo servita, Jesus Cristo é o fundamento último da existência, é aquele que dá sentido à vida e justamente por isso é aquele que move o ser humano eticamente em direção ao próximo, o que torna o homem um ser de comunhão. Esta comunhão, contudo, não está restrita ao espaço da comunidade cristã, ela se estende ao todo da sociedade, por isso que o cristão é também um ser político. Assim, se percebe que uma existência apolítica é incoerente com a fé cristã, pois esta fé está baseada em Jesus Cristo e seu ministério público. Assim, é o próprio Deus feito homem que é assumido como o referencial maior da ética cristã, a qual deve ocorrer a serviço da vida privada e pública.

Contudo, há um abismo entre este referencial ético e a prática cristã. Neste contexto, Jesus destaca-se como a balança ética do pensamento cristão e toda a moral descende do pensar crítico da vida atual frente a figura social e teológica deste Jesus reconhecido como Cristo. No entanto, ao se analisar o distanciamento do cristão da política, realmente vale a pena perguntar se o cristão realmente compreendeu a mensagem proposta por Jesus em sua vida, palavras e ações.

2012. Estes textos não são explorados aqui, mas fazem parte do quadro teórico de nossa pesquisa doutoral em andamento.

36 SINNER, 2007, p. 43.

37 SINNER, 2007, p. 43-44.

38 SINNER, 2007, p. 44.

39 Caberia também uma leitura da teologia do político proposta por Clodovis em sua pesquisa doutoral no horizonte da teologia pública. Ver: BOFF, C. Teologia e prática: teologia do político e suas mediações. 2. ed. Petrópolis: Vozes, 1993. Apesar de mudanças consistentes em seu pensamento (Ver: BRIGHENTI, A. A epistemologia e o método da teologia da libertação no pensamento de Clodovis Boff. Horizonte, Belo Horizonte, v. 11, n. 32, p. 1403-1435, out./dez. 2013), é válido apontar para a seguinte continuidade entre o primeiro e o terceiro Clodovis: o contexto social (modernidade tardia; modernidade fechada e modernidade aberta; sociedade marcadamente religiosa) e a teologia (fé) estão em relação, o que culmina em uma determinada práxis (espiritualidade). 
É neste sentido que a abordagem de Clodovis assume caráter conflitivo e de grande relevância na atualidade. Pois, segundo ele, a fundamentação do sentido da vida está em Deus, ou seja, não está no ser humano, apesar de manifestar-se no humano. Mesmo Deus, sendo fim, não quis findar-se em si mesmo, fazendo-se o fim para o outro. Assim, se a fundamentação do sentido da vida está fora do ser humano, isto o obriga a olhar para fora de si em busca de sentido, e ao olhar para fora é capaz de relacionar-se com Deus e com o próximo. Ora, o humano que significa a existência em si mesmo, em última análise, a partir de C. Boff, niiliza a existência. Seu sentido é significante, mas não suporta a complexidade da vida.

Porém, se o sentido da vida é Deus, e este é também referencial ético do cristão, há esperança de que aqueles que se colocam diante desta fundamentação levem a sério sua responsabilidade diante do próximo. Por outro lado, a fundamentação da ética fora de Cristo é combatida em suas bases por Clodovis, para ele, Deus é o fundamento supremo da vida.

Enfim, do desenvolvimento de Boff, compreendem-se, principalmente, os seguintes pontos: a fundamentação do sentido da vida no Deus cristão; a ideia do sentido enquanto finalidade e fim, ou seja, é a finalidade da vida que dá razão a mesma, e esta é dada por Deus, que é destino e direção, fim e caminho; a compreensão de que a vida humana não é preenchida apenas com aspectos éticos e sociais, mas que somente aberto a espiritualidade e a transcendência é que o homem pode encontrar Deus e ser completado; o entendimento de que ser humano plenamente é ser em Deus e que ser em Deus é ser para o próximo, e, justamente por isso, ser cristão implica em agir cristãmente na sociedade. Assim, o pensamento de Clodovis Boff pode auxiliar no intento de lançar categorias que possam ser pensadas no horizonte de uma teologia que se queira interlocutora das questões emergentes na sociedade.

Dentro do universo da teologia pública, o próprio Rudolf von Sinner corrobora a ideia do sentido da vida em Deus, a partir de uma perspectiva com ênfase trinitária. Para ele:

Deus em sua triunidade representa justamente o elemento específico da fé cristã. É o Deus pericorético-comunitário, Pai, Filho e Espírito Santo - que foi inicialmente adorado na liturgia e doxologia mediante inferências a partir do testemunho bíblico da economia salvífica de Deus e depois foi pensado em concepções teológico-trinitárias - que sustenta os cristãos na vida e na morte. ${ }^{40}$

Compreende-se que o sentido da vida - enquanto significação da existência em dimensão relacional com Deus Trindade que se revela de forma especial em Jesus Cristo -

40 SINNER, R. Hermenêutica ecumênica para um cristianismo plural: reflexões sobre contextualidade e catolicidade. Estudos Teológicos, São Leopoldo, v. 44, n. 2, 2004. p. 55. 
baliza a ética cristã na esfera pública. Esta fonte primordial de sentido é mais do que estatuto teórico, trata-se, em chave cristã, de relacionamento com um Deus vivo, dinâmico e atuante. A relação com o Deus humanado humaniza o humano na medida em que este desencurva-se quenoticamente de si e desdobra-se em amor e solidariedade em favor do próximo, em especial daqueles que sofrem.

\section{Considerações Finais}

O problema da ética hoje requer um questionamento ainda mais profundo do que o debate moral. Nesta direção é possível falar num aspecto geral de crise de valores, crise de existência, crise política, crise ética, etc. A esfera pública é o local em que o rumo da sociedade é debatido e formulado, e escolher se abster desta discussão representa um descaso com a vida do próximo e com a própria. Retirar-se da vida política é negar-se a lutar em prol dos pobres, oprimidos, marginalizados, vitimados, etc., negando assim ao próprio exemplo de Jesus que não existiu humanamente apenas para si, mas se entregou à vida pública delatando as injustiças do Estado e da religião, agindo ética e empaticamente em direção das pessoas, mesmo estrangeiros, doentes, pobres e mulheres, todos estes vitimados e excluídos em seu contexto histórico.

Em última análise, o que Clodovis propõe, em contraposição ao niilismo, é que o ser humano caminhe em direção ao fim último, pois este fim, sendo último, é o fim capaz de dar sentido para a vida. Clodovis propõe uma espiritualidade que anime o ser humano a buscar plenificar sua vida, o que, para ele, só é possível abrindo-se ao transcendente, se colocando sob a fundamentação última da ética e da existência que é identificada com a pessoa de Jesus Cristo, o Sentido que se fez carne.

\section{Referências}

BARRETO, J. A presença pública da Igreja na cidade: análise das práticas pastorais da Igreja Metodista em Belo Horizonte (1982 a 2006) frente aos desafios das transformações socioculturais. Tese (Doutorado). Universidade Metodista de São Paulo, Faculdade de Humanidades e Direito, São Bernardo do Campo, 2013.

BARTH, K. Comunidade cristã e comunidade civil. In: BARTH, K. Dádiva e louvor: ensaios teológicos de Karl Barth. São Leopoldo: Sinodal/EST, 2006.

BOFF, C. O livro do sentido: crise e busca de sentido hoje (parte crítico-analítica). São Paulo: Paulus, 2014.

. Teologia e espiritualidade: por uma teologia que ilumine a mente e inflame o coração. Rev. Pistis Prax. Teol. Pastor., Curitiba, v. 7, n. 1, jan./abr. 2015.

1993.

. Teologia e prática: teologia do político e suas mediações. 2. ed. Petrópolis: Vozes, 
BOFF, L. A urgência de uma ecologia integral. Disponível em:

<https:/ / leonardoboff.wordpress.com/2015/11/10/a-urgencia-de-uma-ecologiaintegral>. Acesso em: 21 jan. 2016.

BRIGHENTI, A. A epistemologia e o método da teologia da libertação no pensamento de Clodovis Boff. Horizonte, Belo Horizonte, v. 11, n. 32, p. 1403-1435, out./dez. 2013.

BUTTELLI, F. E a luta continua: propostas para uma teologia pública libertadora para o desenvolvimento construída em diálogo com a reflexão teológica sul-africana. Tese (Doutorado). Escola Superior de Teologia, Programa de Pós-Graduação, São Leopoldo, 2013.

BUTTELLI, F.; LE BRUYNS, C.; SINNER, R. (Orgs.). Teologia pública no Brasil e na África do Sul: cidadania, interculturalidade e HIV/AIDS. São Leopoldo: Sinodal/Faculdades EST, 2014.

CAVALCANTE, R.; SINNER, R. (Orgs.). Teologia pública: em debate. São Leopoldo: Sinodal/Faculdades EST, 2011.

CAVALCANTE, R.; SINNER, R. A cidade e o gueto: introdução a uma teologia pública protestante e o desafio do neofundamentalismo evangélico no Brasil. São Paulo: Fonte Editorial, 2010.

GMAINER-PRANZL, F.; JACOBSEN, E (Orgs.). Teologia pública: deslocamentos da teologia contemporânea. São Leopoldo: Sinodal/Faculdades EST, 2015.

JACOBSEN, E. Teologia e teoria política: aproximações críticas entre correntes da teologia contemporânea e o pensamento político de Jürgen Habermas. Tese (Doutorado). Faculdades EST, Programa de Pós-Graduação, São Leopoldo, 2015.

JACOBSEN, E.; SINNER, R.; ZWETSCH, R.; KLEIN, R. (Orgs.). Teologia pública: desafios sociais e culturais. São Leopoldo: Sinodal/Faculdades EST, 2012.

JACOBSEN, E.; SINNER, R.; ZWETSCH, R.; STRECK, V. (Orgs.). Teologia pública: desafios éticos e teológicos. São Leopoldo: Sinodal/Faculdades EST, 2012.

SINNER, R. Hermenêutica ecumênica para um cristianismo plural: reflexões sobre contextualidade e catolicidade. Estudos Teológicos, São Leopoldo, v. 44, n. 2, 2004.

. Teologia pública. In: SINNER, R. Confiança e convivência: reflexões éticas e ecumênicas. São Leopoldo: Sinodal, 2007.

. Teologia pública: um olhar global. In: ZWETSCH, R.; CAVALCANTE, R.; SINNER, R. (Orgs.). Teologia Pública: em debate. São Leopoldo: Sinodal/EST, 2011.

. The Churches and democracy in Brazil: towards a public theology focused on citizenship. Eugene: Wipf \& Stock, 2012. 